\title{
$E R G$ rearrangement is present in a subset of transition zone prostatic tumors
}

\author{
Sara M Falzarano ${ }^{1,2}$, Maria Navas ${ }^{3}$, Kelly Simmerman ${ }^{1}$, Eric A Klein ${ }^{4}$, Mark A Rubin ${ }^{5}$, \\ Ming Zhou ${ }^{1,4}$ and Cristina Magi-Galluzzi ${ }^{1,4}$ \\ ${ }^{1}$ Department of Anatomic Pathology, Pathology and Laboratory Medicine Institute, Cleveland Clinic, \\ Cleveland, OH, USA; ${ }^{2}$ Department of Pathology and Human Oncology, University of Siena, Siena, Italy; \\ ${ }^{3}$ Department of Pathology, Summa Health System, Akron, OH, USA; ${ }^{4}$ Glickman Urological \& Kidney \\ Institute, Cleveland Clinic, Cleveland, OH, USA and ${ }^{5}$ Department of Pathology and Laboratory Medicine, \\ Weill Cornell Medical College, New York, NY, USA
}

A majority of prostate cancers exhibit a recurrent gene rearrangement involving chromosome 21. In approximately $90 \%$ of cases, the rearrangement is characterized by fusion of the androgen-regulated gene TMPRSS2 with the oncogene ERG. A recent study suggested that TMPRSS2-ERG gene fusion is lacking in cancers arising from the transition zone of the prostate. A dominant transition zone cancer was detected in $62 / 397(16 \%)$ patients who underwent radical prostatectomy at our institution and were reviewed and mapped by a single pathologist. In $46 / 62$ specimens, a secondary tumor was identified in the peripheral zone of the prostate. A tissue microarray containing both transition and peripheral zone tumors was constructed and evaluated for gene fusion analysis. TMPRSS2-ERG fusion status was determined using a multicolor interphase fluorescence in situ hybridization assay for ERG break-apart. The median age of the patients was 59 years. Prostatectomy Gleason score was 6 in 21, 7 in 34, and $\geq 8$ in 7 cases. Median tumor volume was $200 \mathrm{~mm}^{2}$. TMPRSS2-ERG gene fusion was present in 7/59 (12\%) transition zone, and in $12 / 35(34 \%)$ peripheral zone tumors. Transition zone fusion-positive cases were larger than their negative counterparts. No significant correlation was found between fusion status and Gleason score or pathologic stage. Gene fusion through deletion occurred in $4 / 7$ transition zone and $7 / 12$ peripheral zone tumors. Transition zone prostate cancers are considered biologically and genetically different from peripheral zone tumors. Although $E R G$ rearrangement is more common in peripheral zone tumors, we have detected TMPRSS2-ERG fusion in a subset of transition zone cancers (12\%). The lower frequency of gene fusion in transition zone prostate cancer may suggest distinct molecular alterations from peripheral zone tumors and the association with a high tumor volume may indicate a growth advantage for transition zone tumors harboring the gene fusion. Further studies are necessary to confirm this hypothesis.

Modern Pathology (2010) 23, 1499-1506; doi:10.1038/modpathol.2010.150; published online 6 August 2010

Keywords: ERG rearrangement; peripheral zone; prostate cancer; transition zone

Originally described by Tomlins et $a l^{1}$ in 2005, the fusion of the androgen-regulated gene, transmembrane protease serine 2 (TMPRSS2), and the erythroblastosis virus E26 transforming sequences (ETS) transcription factor gene family members has been reported as a common event in prostate

Correspondence: Dr C Magi-Galluzzi, MD, PhD, Department of Anatomic Pathology, Cleveland Clinic, 9500 Euclid Avenue, L25, Cleveland, OH 44195, USA.

E-mail: magic@ccf.org

Received 14 April 2010; revised 18 May 2010; accepted 27 May 2010; published online 6 August 2010 cancer. ${ }^{2-16}$ v-ets erythroblastosis virus E26 oncogene homolog $(E R G)$ is the most common fusion partner for TMPRSS2; as both genes are located within $3 \mathrm{Mb}$ on chromosome 21, the rearrangement between these two partners occurs either through deletion of the intervening genomic region or through translocation of the intervening sequence to another chromosome. ${ }^{2,3}$

Several studies have suggested a correlation of TMPRSS2-ERG fusion with clinicopathological prognostic indicators, such as early PSA recurrence and seminal vesicle invasion, ${ }^{4}$ higher tumor stage and lymph node metastases, ${ }^{2}$ prostate cancer-specific 
death and higher Gleason score, ${ }^{5,6}$ and greater probability of biochemical relapse. ${ }^{7}$ Moreover, TMPRSS2-ERG fusion by deletion, with or w/o duplication of the fusion sequence, may characterize an aggressive molecular subtype of prostate cancer. ${ }^{2,8,9}$ Some investigators have failed to identify a correlation between $E R G$ fusion and poor prognosis, ${ }^{3,7,10-12}$ whereas others have shown a protective effect of high ERG expression. ${ }^{13}$ Prostate cancer heterogeneity may in part account for the discrepancy between positive and negative studies. ${ }^{14}$

Morphologic and molecular differences between cancers arising from different zones of the prostate gland have been described..$^{15-20}$ All these studies have shown that transition zone tumors may have a different histogenesis, less malignant potential, and, consequently, a more indolent natural history. Recently, transition zone tumors and cancers arising in the most anterior horns of the peripheral zone have been further characterized and grouped together under the designation of 'anterior-predominant prostatic tumors,' to be distinguished from those arising in the posterior peripheral zone. ${ }^{21}$ Lately, Bouye et $a l^{22}$ have studied the zone of origin and patterns of spread of anterior prostate cancers, comprising tumors of transition zone and anterior fibromuscular stroma, and concluded that the contours and location of these cancers are predictable and conform to histological zones boundaries. Transition zone tumors are rarely unifocal and are often associated with peripheral zone cancer foci. ${ }^{16,23}$

Although numerous studies have been published on ERG rearrangements in prostate cancer, few focused on transition zone tumors. Recently, Guo et $a 2^{24}$ have examined 30 transition zone and 30 peripheral zone tumors and reported TMPRSS2$E R G$ gene fusion in $43 \%$ of peripheral zone and in none of the transition zone cases.

The aim of our study was to investigate the TMPRSS2-ERG gene rearrangement status in a larger group of prostate cancers with a dominant nodule located in the transition zone (transition zone prostate cancer), and to compare it with the fusion status of associated peripheral zone tumors (peripheral zone prostate cancer) from the same radical prostatectomy specimens.

\section{Materials and methods}

\section{Study Population, Clinical Data, and Case Selection}

A total of 397 radical prostatectomy specimens, signed out by a single genitourinary pathologist (CMG) between 2004 and 2009, were reviewed. A detailed systematic histological map of each prostate was available in all cases. Inclusion selection criteria required the presence of a dominant prostate cancer located in the transition zone (transition zone prostate cancer), defined as the index (largest) tumor nodule. A cancer was considered as originated from transition zone if $>70 \%$ of its surface was located in this zone, as previously described. ${ }^{15,22}$

A transition zone prostate cancer was identified in 62/397 (16\%) patients who constituted our study population. Patients were diagnosed through PSA screening and/or digital rectal examination. None of them had undergone radiation, androgen deprivation therapy, or transurethral prostatic resection before radical prostatectomy. The demographic and clinicopathological data were collected in an IRB-approved database. In 46 of the 62 cases, a concomitant separate peripheral zone cancer (peripheral zone prostate cancer) was also identified in the corresponding radical prostatectomy specimen.

All radical prostatectomy specimens were weighed, measured, inked, fixed in formalin for 24-48 h, and serially sectioned at $3 \mathrm{~mm}$ intervals perpendicularly to the urethra. The prostate slices were then subdivided in quadrants and labeled to allow for reconstruction as whole-mount sections. Radical prostatectomy specimen weighing $<50 \mathrm{~g}$ were entirely submitted. Standard sections of the prostate, including the apical and bladder neck shave margins, the entire posterior peripheral zone and alternate sections of the anterior zone, and the base of the seminal vesicles were submitted for microscopic examination in cases weighing $\geq 50$ g. Blocks were embedded in paraffin and a $4-\mu \mathrm{m}$ section from each block was stained with hematoxylin and eosin (H\&E). When a dominant transition zone tumor was identified on microscopic examination, additional sections (when available) of the transition zone of the prostate were submitted to ensure proper staging of the lesion.

Outlines of all cancer foci were drawn on the slides under the microscope and then transferred onto a diagrammatic paper representation (map) of all slices in a serial order. From these maps, the histological zones of origin and the relationship between all cancer areas were assessed. Tumors were considered spatially separate if they were $\geq 3 \mathrm{~mm}$ from each others in any single section or $\geq 4 \mathrm{~mm}$ from the closest cancer on the adjacent section above or below, as previously described. ${ }^{25,26}$ For each cancer, Gleason score, tumor volume, extraprostatic extension, seminal vesicle involvement, surgical margin of resection status, and pathologic stage (pT) were separately recorded. Tumor volume at radical prostatectomy was calculated using the sum of the two largest tumor areas, as described previously. ${ }^{27}$

\section{Tissue Microarray Construction}

Transition zone prostate cancer and, when available, a separate tumor from the peripheral zone were selected for tissue microarray construction. Four tissue microarrays representing a total of 99 prostate cancers (62 transition zone and 37 peripheral zone prostate cancers) were manually constructed. Of the 
46 peripheral zone prostate cancers, 9 were not included in the tissue microarray because of small size (median tumor volume $=10 \mathrm{~mm}^{2}$; range $\left.4-20 \mathrm{~mm}^{2}\right)$. Briefly, two to three cores $(1.5 \mathrm{~mm}$ in diameter) for each tumor focus and one for paired non-neoplastic prostatic tissue were taken from the donor paraffin blocks and transferred to the recipient array block. The final tissue microarrays consisted of up to 90 tissue cores per slide, each spaced at $2.2 \mathrm{~mm}$ from one core center to the other. After construction, $4 \mu \mathrm{m}$ sections were cut and a $\mathrm{H} \& \mathrm{E}$ staining was performed on the initial slide to verify the histology.

\section{ERG Gene Rearrangement Assessment by FISH}

A dual-color interphase break-apart FISH assay was performed on the four formalin-fixed and paraffinembedded tissue microarray slides to assess the ERG gene rearrangement status, as previously described. ${ }^{1,2,28}$ Two differentially labeled Bacterial Artificial Chromosome (BAC) FISH probes were used: the biotin-14-dCTP-labeled BAC clone RP1124A11 (eventually conjugated to produce a red signal) for the neighboring $3^{\prime}$ centromeric region of the ERG locus and the digoxigenin-dUTP-labeled BAC clone RP11-372O17 (eventually conjugated to produce a green signal), for the neighboring $5^{\prime}$ telomeric region. According to this break-apart probe system, a nucleus without $E R G$ rearrangement shows two pairs of juxtaposed red and green signals, forming yellow signals; a nucleus with ERG rearrangement through translocation shows one pair of still combined red and green signals (a yellow signal), whereas the other breaks into a single red and a single green signal (split signal); and a nucleus with ERG rearrangement through deletion shows one yellow signal and a single red signal, whereas the green signal $\left(5^{\prime}\right.$ region) is lost (Figure 1$)$. In addition, the presence of multiple copies of the $E R G$ rearrangement sequence as well as the presence of a low-level copy number gain of a normal $E R G$ ( $>2$ copies) was simultaneously assessed in all evaluated nuclei. Tissue hybridization, washing, and fluorescence detection were performed as previously described. ${ }^{29}$

The samples were analyzed under a $\times 100$ oil immersion objective using a Leica DM-RB fluorescence microscope equipped with appropriate filters. The corresponding $\mathrm{H} \& \mathrm{E}$ was available for side-byside comparison with the FISH section. Evaluation of the slides was performed by a pathologist (SMF) and a medical technologist (KS) with experience in analyzing FISH. For each case morphologically intact, nonoverlapping nuclei were scored. A minimum of 50 cancer cells from each tumor was recorded. Cases without 50 evaluable cancer cells and/or with very weak or absent probe signals were reported as insufficient for evaluation. Any case

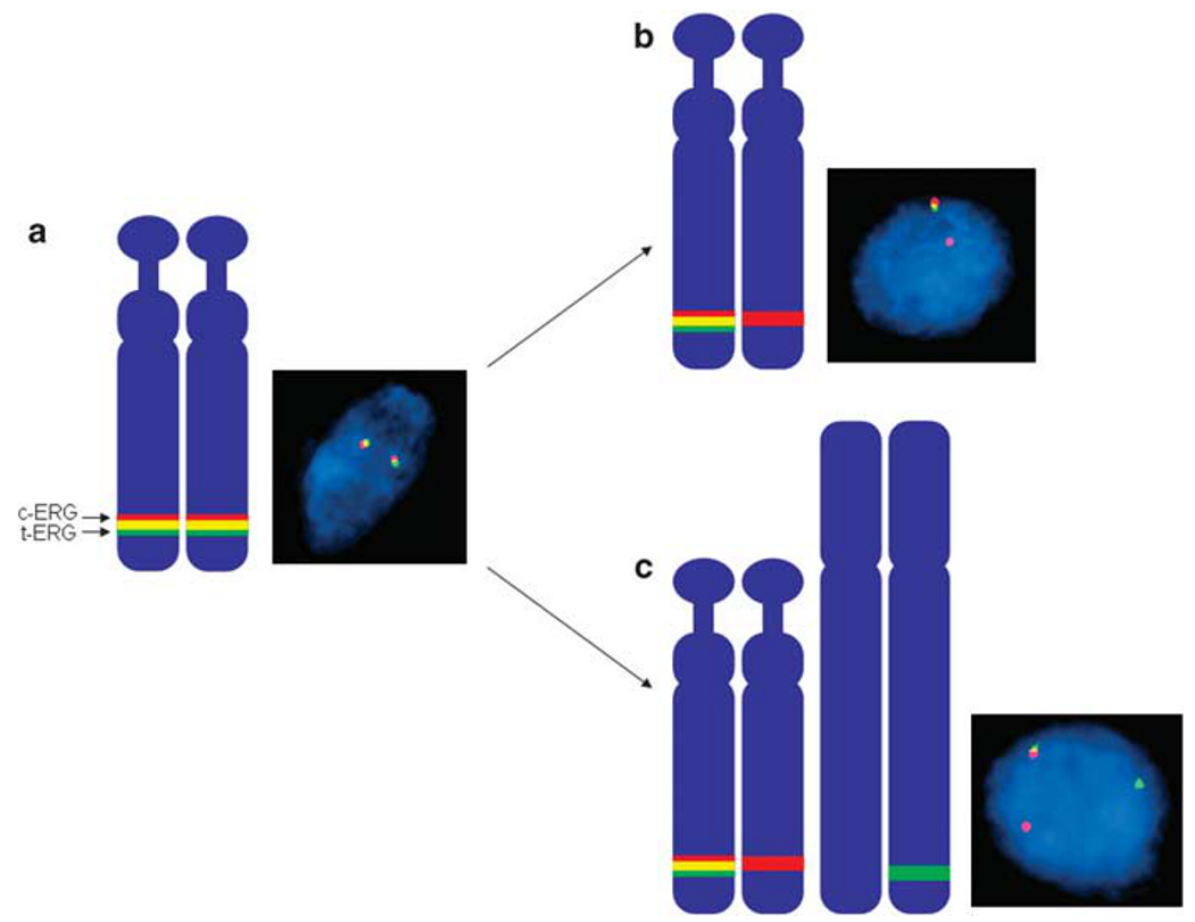

Figure 1 Schematic representation of the dual-color probe FISH break-apart assay for ERG gene rearrangement detection. Two differentially labeled Bacterial Artificial Chromosome (BAC) FISH probes span the neighboring $3^{\prime}$ centromeric (red signal) and $5^{\prime}$ telomeric (green signal) regions of the ERG locus. Un-rearranged ERG loci are visualized in the interphase nucleus as immediately adjacent green and red signals, forming yellow fusion signals (a). The rearrangement eventually results in the break apart of the yellow signal of one of the two alleles, with loss (b) or translocation (c) of the lone green $5^{\prime} E R G$ signal to another chromosome. 
with ERG signal abnormalities in $>10 \%$ of the neoplastic cells was scored as positive.

\section{Results}

The median age of the 62 patients included in the study was 59 years (range 42-81). The overall Gleason score in the radical prostatectomy specimens was 6 in 21 (34\%), 7 in $34(55 \%), 7$ with tertiary pattern 5 in $3(5 \%)$, and 9 in $4(6 \%)$ cases. The median tumor volume was $200 \mathrm{~mm}^{2}$ (range 25-1140). Prostate cancer was confined to the gland (pT2) in 44/62 (71\%) cases. Extraprostatic extension was detected in $14(23 \%)$ cases and bladder neck involvement in $4(6 \%)$ cases, which were all classified as pT3a. None of the cases showed seminal vesicle involvement. The pathologic stage was determined by the dominant transition zone cancer in $60(97 \%)$ cases. In the remaining two cases, the peripheral zone cancer, although

Table 1 Pathological characteristics of transition zone and peripheral zone prostate cancers

\begin{tabular}{lcc}
\hline Parameter & $\begin{array}{c}\text { Transition zone } \\
\text { prostate cancer } \\
(\mathrm{n}=62)\end{array}$ & $\begin{array}{c}\text { Peripheral zone } \\
\text { prostate cancer } \\
\text { (n=46) }\end{array}$ \\
\hline Gleason score 6 & 23 & 38 \\
Gleason score 7 & 32 & 7 \\
$\begin{array}{l}\text { Gleason score 7+tertiary } \\
\text { pattern 5 }\end{array}$ & 3 & 0 \\
Gleason score 9 & 4 & 1 \\
pT2 & 46 & 44 \\
pT3 & 16 & 2 \\
Median tumor volume & $200(25-1140)$ & $28.5(4-350)$ \\
$\left(\mathrm{mm}^{2}\right.$ ), range & & \\
\hline
\end{tabular}

smaller (tumor volume $=350$ vs 800 , and tumor volume $=300$ vs $500 \mathrm{~mm}^{2}$, respectively), involved the extraprostatic adipose tissue (pT3), whereas the transition zone prostate cancer was organ confined (pT2).

The pathological features of the 62 transition zone prostate cancers and 46 peripheral zone prostate cancers identified at radical prostatectomy are summarized in Table 1. Gleason score for the transition zone prostate cancers and peripheral zone prostate cancers was 6 in 23 and 38, 7 in 32 and 7, 7 with tertiary pattern 5 in 3 and 0 , and Gleason score 9 in 4 and 1, respectively. In all, $46(74 \%)$ of the transition zone prostate cancers and $44(96 \%)$ of the peripheral zone prostate cancers were stage pT2. The median tumor volume was $200 \mathrm{~mm}^{2}$ (range $25-$ $1140)$ and $28 \mathrm{~mm}^{2}(4-350)$ for the transition and peripheral zone tumors, respectively. Thus, 59 of the 62 transition zone prostate cancers and 35 of the 37 peripheral zone prostate cancers included in the tissue microarrays were informative for fusion status.

TMPRSS2-ERG gene fusion was present in $7 / 59$ $(12 \%)$ transition zone prostate cancers and 12/35 (34\%) peripheral zone prostate cancers. Among positive cases, gene fusion occurred through deletion in $4 / 7(57 \%)$ transition zone prostate cancers and in $7 / 12(58 \%)$ peripheral zone prostate cancers and through translocation in $3 / 7(43 \%)$ transition zone prostate cancers and in 5/12 (42\%) peripheral zone prostate cancers (Table 2). Duplication of the rearranged sequence with deletion was observed in only one focus from the peripheral zone; low-level copy number gain was found in 10/59 (17\%) transition zone prostate cancers and in 2/35 (6\%) peripheral zone prostate cancers. In three patients, the TMPRSS2-ERG gene fusion was present in both

Table 2 Pathological characteristics of positive cases by FISH

\begin{tabular}{|c|c|c|c|c|c|c|c|c|}
\hline \multirow[t]{2}{*}{ Case no. } & \multicolumn{4}{|c|}{ Transition zone prostate cancer } & \multicolumn{4}{|c|}{ Peripheral zone prostate cancer } \\
\hline & $\begin{array}{l}\text { Gleason } \\
\text { score }\end{array}$ & $\begin{array}{l}\text { Tumor volume } \\
\qquad\left(\mathrm{mm}^{2}\right)\end{array}$ & pT stage & ERG status & $\begin{array}{l}\text { Gleason } \\
\text { score }\end{array}$ & $\begin{array}{l}\text { Tumor volume } \\
\qquad\left(\mathrm{mm}^{2}\right)\end{array}$ & pT stage & ERG status \\
\hline 1 & 7 & 1140 & 2 & Translocation & - & - & - & - \\
\hline 2 & 7 & 700 & 3 & Deletion & - & - & - & - \\
\hline 3 & 6 & 110 & 2 & Translocation & 6 & 10 & 2 & Deletion \\
\hline 4 & 7 & 796 & 3 & Deletion & 6 & 150 & 2 & Negative \\
\hline 5 & 7 & 577 & 2 & Deletion & 6 & 40 & 2 & Deletion \\
\hline 6 & 7 & 800 & 2 & Deletion & 7 & 350 & 3 & Translocation \\
\hline 7 & 6 & 210 & 2 & Translocation & 6 & 4 & 2 & $\mathrm{~N} / \mathrm{A}^{\mathrm{a}}$ \\
\hline 8 & 6 & 80 & 2 & Negative & 6 & 40 & 2 & Deletion \\
\hline 9 & 6 & 150 & 2 & Negative & 6 & 50 & 2 & Translocation \\
\hline 10 & 7 & 180 & 2 & Negative & 6 & 25 & 2 & Deletion \\
\hline 11 & 7 & 200 & 2 & Negative & 6 & 25 & 2 & Translocation \\
\hline 12 & 7 & 200 & 2 & Negative & 6 & 70 & 2 & Translocation \\
\hline 13 & 7 & 210 & 2 & Negative & 6 & 44 & 2 & Deletion \\
\hline 14 & 6 & 246 & 2 & Negative & 6 & 45 & 2 & Translocation \\
\hline 15 & 7 & 270 & 3 & Negative & 6 & 15 & 2 & Deletion \\
\hline 16 & 7 & 280 & 2 & Negative & 6 & 65 & 2 & Deletion \\
\hline
\end{tabular}

\footnotetext{
${ }^{\mathrm{a}}$ Peripheral zone focus was too small and not included in tissue microarray.
} 
Table 3 Pathologic features of transition zone and peripheral zone prostate cancers informative for FISH

\begin{tabular}{|c|c|c|c|c|}
\hline \multirow[b]{2}{*}{ Parameter } & \multicolumn{2}{|c|}{ Peripheral zone prostate cancer $(\mathrm{n}=35)$} & \multicolumn{2}{|c|}{ Transition zone prostate cancer $(\mathrm{n}=59)$} \\
\hline & $F I S H+(\mathrm{n}=12)$ & $F I S H-(\mathrm{n}=23)$ & $F I S H+(\mathrm{n}=7)$ & $F I S H-(\mathrm{n}=52)$ \\
\hline Gleason score 6 & 11 & 17 & 2 & 19 \\
\hline Gleason score 7 & 1 & 5 & 5 & 26 \\
\hline Gleason score $>7$ & 0 & 1 & 0 & 7 \\
\hline pT2 & 11 & 22 & 5 & 38 \\
\hline pT3 & 1 & 1 & 2 & 14 \\
\hline Median tumor volume, $\mathrm{mm}^{2}$ (range) & $42(10-350)$ & $45(5-300)$ & $700(110-1140)$ & $200(25-700)$ \\
\hline
\end{tabular}

transition zone and peripheral zone tumors: in one case, the rearrangement occurred through deletion in both tumors, and in the other two cases, deletion was present either in the transition zone or in the peripheral zone (Table 2).

The pathological features of the cases informative by FISH analysis are summarized in Table 3. Of the seven positive transition zone prostate cancers, two $(29 \%)$ were Gleason score 6 and five $(71 \%)$ were Gleason score 7; two of the transition zone prostate cancers (29\%) involved extraprostatic tissue (pT3); four $(57 \%)$ cases were organ confined; in one case $(14 \%)$ the tumor involved the surgical margin of resection (Figure 2). The transition zone prostate cancer positive cases were significantly larger than their negative counterparts (median tumor volume: 700 vs $\left.200 \mathrm{~mm}^{2}\right)(P<0.001$; $t$-test $)$. Of the 12 positive peripheral zone prostate cancers, all except one $(92 \%)$ were Gleason score 6 and organ confined (pT2). The remaining case (8\%) was Gleason score 7 and extended into the extraprostatic soft tissue (pT3). There was no difference in tumor volume between FISH-positive and FISH-negative peripheral zone prostate cancers $(P=0.884)$. We found no significant correlation between fusion status and either Gleason score or pathologic stage.

\section{Discussion}

Prostate cancer is a clinically heterogeneous disease with marked variability in outcome. The recent identification of the rearrangement involving the androgen-regulated gene TMPRSS2 and members of the ETS transcription factor family provides a mechanism for overexpression of ETS genes in prostate cancer. TMPRSS2 is highly expressed in prostate cancer and contains androgen response elements in the promoter. ${ }^{30}$

TMPRSS2-ERG gene fusion has been described in 43 to $55 \%$ of primary prostate cancers cases. ${ }^{1,2,31-33}$ Most studies evaluated clinically localized prostate cancer samples, but did not take into account the zonal subdivision of the prostate gland and the zone of origin of the tumors.

The zonal division of the prostate proposed by McNeal et $a l^{15}$ has been widely accepted. In their model the prostate is divided in four zones:

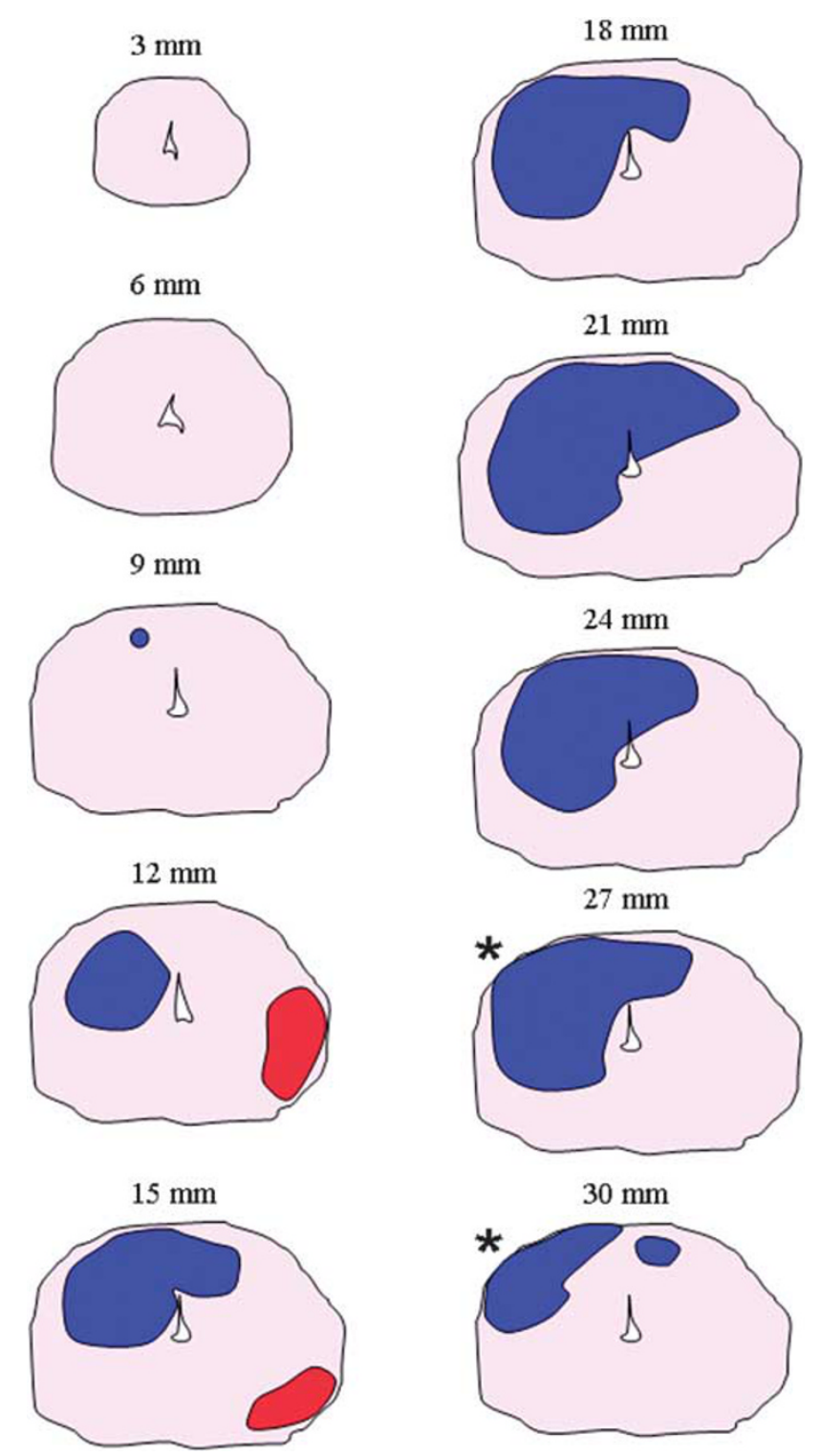

Figure 2 Diagrammatic paper representation (map) of prostate slices in serial order. The transition zone dominant nodule (blue) is positive for $E R G$ rearrangement through deletion, whereas the secondary peripheral zone cancer (red) is not. The transition zone prostate cancer involves the surgical margin of resection $\left(^{*}\right)$.

peripheral zone, transition zone, central zone, and anterior fibromuscular stroma. The prostatic zones appear to differ not only morphologically, but also in 
the diseases that they harbor. ${ }^{34}$ Adenocarcinoma of the prostate arises mostly in the peripheral zone whereas the non-malignant overgrowth of benign prostatic hyperplasia occurs exclusively in the transition zone. Considering that prostate cancer is predominantly peripheral zone associated, it is reasonable to assume that most of the data published on ERG fusion status refer to peripheral zone prostate cancers.

Prostate cancers arising from the transition zone represent $25-30 \%$ of cancers in radical prostatectomy series. ${ }^{35}$ Most tumors discovered incidentally during transurethral resection of the prostate are found in the transition zone. Transition zone tumors tend to stay in the zone where they first developed until they have reached a volume between 2 and $4 \mathrm{~cm}^{3}{ }^{36}$ Transition zone cancers are usually considered to have a better outcome at same volume and grade than their peripheral zone counterparts. ${ }^{37-39}$

Demichelis et $a l^{5}$ characterized the TMPRSS2$E R G$ fusion status in a population-based cohort of men with early prostate cancer diagnosed by transurethral resection of the prostate or transvesical adenoma enucleation for symptomatic benign prostatic hyperplasia. Although the morphology of prostate cancer was not detailed in this study, a majority of the prostate cancers probably represented transition zone prostate cancer. The frequency of TMPRSS2-ERG fusion detected in these transition zone tumors was $15 \%(17 / 111)$. Recently, Guo et $a l^{24}$ have found no TMPRSS2-ERG gene fusion rearrangement in any of the 30 transition zone prostate cancers examined.

In this study we investigated the TMPRSS2-ERG gene rearrangement status in a group of patients with a dominant transition zone prostate cancer detected on radical prostatectomy, and compared it with the fusion status of concomitant peripheral zone tumors when present in the same specimen. Cases with prostate cancer arising in both transition and peripheral zones of the gland were included only if the transition zone component was larger (index tumor) than the peripheral zone one.

Similar to Demichelis et $a l^{5}$ and in contrast to Guo et $a l,{ }^{24}$ we detected TMPRSS2-ERG gene fusion in 7 $(12 \%)$ informative transition zone tumors. Of the fusion-positive transition zone prostate cancers, two were Gleason score 6 and five were Gleason score 7; two involved extraprostatic tissue, four were organ confined, and in one case the tumor involved the surgical margin of resection. Contrary to Demichelis et $a l,{ }^{5}$ we found no correlation between TMPRSS2-ERG fusion-positive tumors and Gleason score, although our number of positive cases was smaller.

We detected ERG rearrangements in only $34 \%$ of peripheral zone prostate cancers. This frequency of TMPRSS2-ERG fusion is similar to the value of $30 \%$ (134 of 445) found by Attard et al, ${ }^{8}$ but lower than the value of $49 \%$ (58 of 118) found by Perner et $a l^{2}$ and 43\% (13 of 30) found by Guo et al, ${ }^{24}$ who also assessed $E R G$ gene alterations using a FISH breakapart assay. As the incidence of $E R G$ gene alterations have been linked to clinical stage and Gleason score, these differences may be explained, at least in part, by the distinct clinical compositions of the prostate tumor sets surveyed in each study, as suggested by Attard et al. ${ }^{8}$

Among our positive cases, deletion, rather than translocation, was found to be the main mechanism for TMPRSS2-ERG gene fusion in both transition zone prostate cancers (57\%) and peripheral zone prostate cancers $(58 \%)$, as previously reported in other studies. ${ }^{2,24,25,33,40,41}$

We observed duplication of the rearranged sequence with deletion in one prostate cancer from the peripheral zone. Yoshimoto et $a l^{3}$ observed duplication of TMPRSS2-ERG fusion in $6 \%$ of tumors and reported an association with worse prognosis. Similarly, Attard et $a l^{8}$ found that duplication of the TMPRSS2-ERG fusion together with interstitial deletion of sequences $5^{\prime}$ to $E R G$ exhibited extremely poor cause-specific survival. ${ }^{8}$ Our peripheral zone tumor with duplication was Gleason score 6 and was confined to the prostate.

Low-level copy number gain of a normal $E R G$ was found in $10 / 59(17 \%)$ of our transition zone prostate cancer and in 2/35 (6\%) peripheral zone prostate cancer and seemed to be associated with larger tumor volume and higher Gleason score. Our findings are in keeping with what has been previously shown. Albadine et $a l^{42}$ have recently reported a trend toward higher rate of low-level copy number gain in non-minute prostatic adenocarcinomas $(10 \%)$ compared with minute prostatic adenocarcinomas $(0 \%)$ and suggested that gain of $E R G$ copy number is potentially acquired during tumor progression.

The lower frequency of gene fusion in transition zone prostate cancer tumors suggests a different carcinogenic pathway than in peripheral zone prostate cancers. Our detection of TMPRSS2-ERG gene fusion in transition zone prostate cancer, in contrast to the findings of Guo et $a,^{24}$ can be explained in part by the larger sample size and possibly by the size of the tumors. The median size of transition zone tumors studied by Guo et $a l^{24}$ was $4 \mathrm{~cm}^{3}$ (range $0.5-12.8 \mathrm{~cm}^{3}$ ), and was determined by multiplying the sum of the tumor areas of all crosssections by the section thickness. On the other end, we calculated the tumor volume using the sum of the two largest tumor areas. Although the two methods of calculation are different and the values are difficult to compare, we found that fusionpositive transition zone prostate cancers were significantly larger than their negative counterparts (median tumor volume: 700 vs $200 \mathrm{~mm}^{2} ; P<0.001$ ). Our finding is in keeping with what was recently presented at the GU ASCO meeting by Aubin et $a l^{43}$. These researchers evaluated the expression of TMPRSS2-ERG in post-digital rectal exam urine for the diagnosis of prostate cancer and found an 
association of TMPRSS2-ERG scores with tumor volume.

In view of this finding, we hypothesize that transition zone tumors harboring the gene fusion may have a growth advantage. One could also speculate that in view of the larger volume, fusionpositive transition zone tumors might come to clinical attention more so than fusion-negative cancer; in other words, the fast-growing tumors are detected more often than the slower-growing fusionnegative tumors. Perhaps this might explain why the fusion-positive cases detected in transurethral resection of the prostate samples from a large Watchful Waiting cohort of men by Demichelis et $a l^{5}$ tended to do worse (ie, 41 of 46 were associated with aggressive disease) than their negative counterparts. This could potentially be important from the perspective of the detection of more aggressive tumors.

Transition zone prostate tumors are believed to be indolent and tend to present with larger tumor volumes. Previous studies have explored potential differences between the zones of the prostate, and found that indeed the different zones of the prostate possess distinct gene expression profiles that might be responsible for their diverse clinical behaviors. ${ }^{19,20}$ Hyperplastic growth of the prostate transition zone associated with clinical benign prostatic hyperplasia may be the result of the abnormal expression of key androgen-responsive genes, which lead to an imbalance between cell division and death. ${ }^{44}$ Genes regulated by androgenic hormones are of critical importance for the normal physiological function of the human prostate gland, and they contribute to the development and progression of prostate carcinoma.

Our study is limited by a relatively small sample size, although it is so far the largest study of wellcharacterized transition zone prostate cancers. In addition, we have studied only TMPRSS2-ERG, one of the most frequent rearrangements encountered in prostate cancer, although other rearrangements might be informative in differentiating the clinical behavior of tumors arising in different zones of the prostate.

Although present in transition zone prostate cancer, TMPRSS2-ERG gene fusion does not have the same incidence as it does in peripheral zone prostate cancer. This difference needs to be explored as it may possibly be explained by genetic and biologic peculiarities of each zone of the gland and the cancers that they give rise to. As TMPRSS2-ERG fusion gene has been detected in a proportion of HGPIN lesions and it seems clear that this molecular rearrangement is an early event in prostate cancer development and/or progression, ${ }^{45,46}$ we hypothesized that the altered expression of ETS genes resulting from the TMPRSS2-ERG rearrangement may impart a growth advantage to prostate cancer. Further studies are necessary to address this hypothesis.

\section{Disclosure/conflict of interest}

The authors declare no conflict of interest.

\section{References}

1 Tomlins SA, Rhodes DR, Perner S, et al. Recurrent fusion of TMPRSS2 and ETS transcription factor genes in prostate cancer. Science 2005;310:644-648.

2 Perner S, Demichelis F, Beroukhim R, et al. TMPRSS2:ERG fusion-associated deletions provide insight into the heterogeneity of prostate cancer. Cancer Res 2006;66:8337-8341.

3 Yoshimoto M, Joshua AM, Chilton-Macneill S, et al. Three-color FISH analysis of TMPRSS2/ERG fusions in prostate cancer indicates that genomic microdeletion of chromosome 21 is associated with rearrangement. Neoplasia 2006;8:465-469.

4 Wang J, Cai Y, Ren C, et al. Expression of variant TMPRSS2/ERG fusion messenger RNAs is associated with aggressive prostate cancer. Cancer Res 2006;66: 8347-8351.

5 Demichelis F, Fall K, Perner S, et al. TMPRSS2:ERG gene fusion associated with lethal prostate cancer in a watchful waiting cohort. Oncogene 2007;26: 4596-4599.

6 Rajput AB, Miller MA, De Luca A, et al. Frequency of the TMPRSS2:ERG gene fusion is increased in moderate to poorly differentiated prostate cancers. J Clin Pathol 2007;60:1238-1243.

7 Nam RK, Sugar L, Wang Z, et al. Expression of TMPRSS2:ERG gene fusion in prostate cancer cells is an important prognostic factor for cancer progression. Cancer Biol Ther 2007;6:40-45.

8 Attard G, Clark J, Ambroisine L, et al. Duplication of the fusion of TMPRSS2 to ERG sequences identifies fatal human prostate cancer. Oncogene 2008;27: 253-263.

9 Mehra R, Tomlins SA, Yu J, et al. Characterization of TMPRSS2-ETS gene aberrations in androgen-independent metastatic prostate cancer. Cancer Res 2008;68: 3584-3590.

10 Gopalan A, Leversha MA, Satagopan JM, et al. TMPRSS2-ERG gene fusion is not associated with outcome in patients treated by prostatectomy. Cancer Res 2009;69:1400-1406.

11 Lapointe J, Kim YH, Miller MA, et al. A variant TMPRSS2 isoform and ERG fusion product in prostate cancer with implications for molecular diagnosis. Mod Pathol 2007;20:467-473.

12 Rostad K, Hellwinkel OJ, Haukaas SA, et al. TMPRSS2:ERG fusion transcripts in urine from prostate cancer patients correlate with a less favorable prognosis. APMIS 2009;117:575-582.

13 Petrovics G, Liu A, Shaheduzzaman S, et al. Frequent overexpression of ETS-related gene-1 (ERG1) in prostate cancer transcriptome. Oncogene 2005;24: 3847-3852.

14 Sboner A, Demichelis F, Calza S, et al. Molecular sampling of prostate cancer: a dilemma for predicting disease progression. BMC Med Genomics 2010;3:8.

15 McNeal JE, Redwine EA, Freiha FS, et al. Zonal distribution of prostatic adenocarcinoma. Correlation with histologic pattern and direction of spread. Am J Surg Pathol 1988;12:897-906. 
16 Greene DR, Wheeler TM, Egawa S, et al. A comparison of the morphological features of cancer arising in the transition zone and in the peripheral zone of the prostate. J Urol 1991;146:1069-1076.

17 Greene DR, Wheeler TM, Egawa S, et al. Relationship between clinical stage and histological zone of origin in early prostate cancer: morphometric analysis. Br J Urol 1991;68:499-509.

18 Erbersdobler A, Fritz H, Schnoger S, et al. Tumour grade, proliferation, apoptosis, microvessel density, p53, and bcl-2 in prostate cancers: differences between tumours located in the transition zone and in the peripheral zone. Eur Urol 2002;41:40-46.

19 van der Heul-Nieuwenhuijsen L, Hendriksen PJ, van der Kwast TH, et al. Gene expression profiling of the human prostate zones. BJU Int 2006;98:886-897.

20 Noel EE, Ragavan N, Walsh MJ, et al. Differential gene expression in the peripheral zone compared to the transition zone of the human prostate gland. Prostate Cancer Prostatic Dis 2008;11:173-180.

21 Al-Ahmadie HA, Tickoo SK, Olgac S, et al. Anteriorpredominant prostatic tumors: zone of origin and pathologic outcomes at radical prostatectomy. Am J Surg Pathol 2008;32:229-235.

22 Bouye S, Potiron E, Puech P, et al. Transition zone and anterior stromal prostate cancers: zone of origin and intraprostatic patterns of spread at histopathology. Prostate 2009;69:105-113.

23 Chen ME, Johnston DA, Tang K, et al. Detailed mapping of prostate carcinoma foci: biopsy strategy implications. Cancer 2000;89:1800-1809.

24 Guo CC, Zuo G, Cao D, et al. Prostate cancer of transition zone origin lacks TMPRSS2-ERG gene fusion. Mod Pathol 2009;22:866-871.

25 Mehra R, Han B, Tomlins SA, et al. Heterogeneity of TMPRSS2 gene rearrangements in multifocal prostate adenocarcinoma: molecular evidence for an independent group of diseases. Cancer Res 2007;67:7991-7995.

26 Wise AM, Stamey TA, McNeal JE, et al. Morphologic and clinical significance of multifocal prostate cancers in radical prostatectomy specimens. Urology 2002; 60:264-269.

27 Renshaw AA, Chang H, D'Amico AV. Estimation of tumor volume in radical prostatectomy specimens in routine clinical practice. Am J Clin Pathol 1997;107:704-708.

28 Perner S, Mosquera JM, Demichelis F, et al. TMPRSS2ERG fusion prostate cancer: an early molecular event associated with invasion. Am J Surg Pathol 2007;31: 882-888.

29 Rubin MA, Varambally S, Beroukhim R, et al. Overexpression, amplification, and androgen regulation of TPD52 in prostate cancer. Cancer Res 2004;64: 3814-3822.

30 Lin B, Ferguson C, White JT, et al. Prostate-localized and androgen-regulated expression of the membranebound serine protease TMPRSS2. Cancer Res 1999;59: 4180-4184.

31 Esgueva R, Perner S, C JL, et al. Prevalence of TMPRSS2-ERG and SLC45A3-ERG gene fusions in a large prostatectomy cohort. Mod Pathol 2010;23: 539-546.

32 Mosquera JM, Perner S, Demichelis F, et al. Morphological features of TMPRSS2-ERG gene fusion prostate cancer. J Pathol 2007;212:91-101.

$33 \mathrm{Tu}$ JJ, Rohan S, Kao J, et al. Gene fusions between TMPRSS2 and ETS family genes in prostate cancer: frequency and transcript variant analysis by RT-PCR and FISH on paraffin-embedded tissues. Mod Pathol 2007;20:921-928.

34 Shannon BA, McNeal JE, Cohen RJ. Transition zone carcinoma of the prostate gland: a common indolent tumour type that occasionally manifests aggressive behaviour. Pathology 2003;35:467-471.

35 Reissigl A, Pointner J, Strasser H, et al. Frequency and clinical significance of transition zone cancer in prostate cancer screening. Prostate 1997;30:130-135.

36 McNeal JE, Haillot O. Patterns of spread of adenocarcinoma in the prostate as related to cancer volume. Prostate 2001;49:48-57.

37 Noguchi M, Stamey TA, Neal JE, et al. An analysis of 148 consecutive transition zone cancers: clinical and histological characteristics. J Urol 2000;163: 1751-1755.

38 Augustin H, Erbersdobler A, Graefen M, et al. Biochemical recurrence following radical prostatectomy: a comparison between prostate cancers located in different anatomical zones. Prostate 2003;55:48-54.

39 King CR, Ferrari M, Brooks JD. Prognostic significance of prostate cancer originating from the transition zone. Urol Oncol 2009;27:592-597.

40 Yoshimoto M, Joshua AM, Cunha IW, et al. Absence of TMPRSS2:ERG fusions and PTEN losses in prostate cancer is associated with a favorable outcome. Mod Pathol 2008;21:1451-1460.

41 Han B, Mehra R, Suleman K, et al. Characterization of ETS gene aberrations in select histologic variants of prostate carcinoma. Mod Pathol 2009;22:1176-1185.

42 Albadine R, Latour M, Toubaji A, et al. TMPRSS2-ERG gene fusion status in minute (minimal) prostatic adenocarcinoma. Mod Pathol 2009;22:1415-1422.

43 Aubin SM, Tomlins SA, Sakamoto K, et al. Urine measurement of TMPRSS2:ERG for the early detection of significant prostate cancer. ASCO 2010 Genitourinary Cancers Symposium 5-7 March 2010, San Francisco (abstract).

44 Love HD, Booton SE, Boone BE, et al. Androgen regulated genes in human prostate xenografts in mice: relation to $\mathrm{BPH}$ and prostate cancer. PLoS ONE 2009; 4:e8384.

45 Mosquera JM, Perner S, Genega EM, et al. Characterization of TMPRSS2-ERG fusion high-grade prostatic intraepithelial neoplasia and potential clinical implications. Clin Cancer Res 2008;14:3380-3385.

46 Cerveira N, Ribeiro FR, Peixoto A, et al. TMPRSS2-ERG gene fusion causing ERG overexpression precedes chromosome copy number changes in prostate carcinomas and paired HGPIN lesions. Neoplasia 2006; 8:826-832. 